\title{
O CLIMA E A PAISAGEM DA BACIA HIDROGRÁFICA DO LITORAL - ESTADO DO CEARÁ
}

\author{
CLIMATE AND LANDSCAPE OF THE BASIN OF THE COAST - STATE OF CEARÁ \\ CLIMA EN EL PAISAJE DE LA CUENCA DE LA COSTA - ESTADO DE CEARÁ \\ Fátima Maria Soares Kelting - UFC - Fortaleza - Brasil \\ doninha@ufc.br
}

\begin{abstract}
Resumo
A pesquisa tem por finalidade identificar as paisagens da bacia do Litoral do Estado do Ceará, utilizando como base a distribuição pluviométrica e a ação das massas atmosféricas num regime climático semiárido. Para compreender como as paisagens estão espacializadas ao longo da bacia, utilizou-se como parâmetros de análise uma série pluviométrica entre 1971-2007, em que, a partir das informações fornecidas pelos dados obtidos de diversas fontes, foi possível identificar como as chuvas estão distribuídas no tempo e espaço e qual a sua influência para a formação das paisagens e para a vida da população que vive na região.
\end{abstract}

Palavras-chave: Bacia do litoral. Estado do Ceará. Paisagem. Clima.

\section{Abstract}

The research has for purpose to identify the landscapes of the basin of the Coast of the State of Ceará, using as base the pluviometric precipitation and the action of the atmospheric masses in a regime climatic semiarid. To understand as the landscapes they are spatiality located in the space along the basin, it was used as analysis parameters a pluviometric series among 1971-2007 in that, starting from the information supplied by the obtained data of several sources, it was possible to identify as the rains they are distributed in the time and space, and which your influence for the formation of the landscapes and for the life of the population that lives in the area.

Key words: Basin of the coast. State of Ceará. Landscape. Climate.

\section{Resumen}

La investigación apunta a identificar los paisajes de las cuencas de la costa del Estado de Ceará, utilizando como base la distribución de las precipitaciones y la acción de las masas atmosféricas en semi-régimen de clima árido. Para entender cómo los paisajes son espacializada a lo largo de la cuenca se utiliza como parámetros de análisis de una lluvia serie entre 1971-2007, donde, a partir de la información proporcionada por los datos obtenidos de diversas fuentes, podría ser identificado como las lluvias se distribuyen en tiempo y espacio y cuál es su influencia para la formación de los paisajes y la vida de las personas que viven en la región.

Palabras clave: Costa de la cuenca. Estado de Ceará. Paisaje. El clima. 


\section{Introdução}

A presente pesquisa faz um estudo de identificação de paisagens a partir de parâmetros físicos naturais. Neste trabalho usou-se como parâmetro a distribuição e o comportamento das chuvas, e sua influência na formação das paisagens. A área escolhida foi a bacia hidrográfica do litoral - Estado do Ceará. A área de drenagem ocupa 9.622 km², estando situada entre as bacias hidrográficas do Curu e do Acaraú. A bacia hidrográfica foi utilizada como critério de delimitação espacial por apresentar limites naturais bem definidos. Para a análise foram observados dados pluviométricos entre o período de 1971-2007, com a finalidade de determinar o comportamento cíclico das chuvas no tempo e no espaço. A partir da submissão dos dados à análise estatística, identificando a média, o desvio padrão e o coeficiente de variância, foi possível identificar nos índices os intervalos de flutuação temporal e espacial das chuvas. A ciclidade dos períodos das pluviosidades vai ser determinante para a aridez ao longo da bacia, tendo em vista serem as ações atmosféricas globais, seu arranjo espacial e sua topografia fatores que limitam a sua distribuição.

Estudar a série pluviométrica possibilitou relacionar fatores que interferem nos períodos de chuva, tornando-a cíclica e perceptível quando se observa a paisagem.

A compreensão de como as estações chuvosas e as secas transcorrem ao longo da série estudada permite-nos compreender o regime climático semiárido, que apresenta exatamente esse comportamento flutuante de estações secas e de grandes chuvas.

No caso da bacia hidrográfica do litoral, a distribuição temporal e espacial das chuvas ratifica o tipo climático de semiaridez, informação que vai contribuir para o conhecimento do ritmo das precipitações, sobretudo de como a sociedade utiliza a potencialidade natural da área.

\section{0 clima define a paisagem}

A paisagem constitui a materialização dos sistemas ambientais que são visualizados e apreendidos por nós, tendo sua origem no passado climático e tectônico do planeta e nos processos que atuam constantemente criando e recriando novos contornos na natureza. 
Ao vislumbrar uma paisagem, no caso específico a bacia hidrográfica do litoral, podemos identificar em seus $9.622 \mathrm{~km}$ a formação de paisagens com forte controle do regime climático semi-árido. Nesse regime, as estações chuvosas ou as secas constituem o seu padrão, sendo essa variabilidade a característica deste clima, que recebe influência de força gravitacional, geomagnética e rotacional que atuam no planeta.

A sazonalidade das estações está diretamente ligada aos fatores atmosféricos de escala global, eventos que ocorrem em período cíclico, cuja intensidade e magnitude vão depender da energia absorvida pelo oceano e seus efeitos propagadores da atmosfera. $\mathrm{O}$ volume das chuvas está diretamente relacionado à sua distribuição espacial, à quantidade de energia que movimenta a atmosfera, que sofre influência da litosfera, hidrosfera e biosfera e, como reflexo, influencia na formação das paisagens.

Segundo Souza et al. (2000) e Marengo et al. (2001), a variabilidade climática depende da ação da Zona de Convergência do Atlântico (ZCAS), que atua durante o verão, e da Zona de Convergência Intertropical (ZCIT), atuante no outono. Os autores observaram que essas oscilações recebem interferência da Oscilação de Madden-Julian (OMJ), Madden; Jullian, (1994). Essa oscilação consiste numa célula que atua em escala global e se propaga em faixa zonal para leste, segundo Weikmann et al. (1985). Sua ocorrência é observada no Oceano Índico e Pacífico Oeste, atingindo a Indonésia e estendendo-se até a costa oeste da América do Sul. Segundo Carvalho et al. (2004), a ação da OMJ interfere na ZCAS e na ZCIT, ocasionando uma variabilidade espacial do evento e de precipitação. Essa perturbação atinge o centro-leste da América do Sul, região da Amazônia. A baixa frequência das convecções tem atuação global e provoca interferência na Oscilação do Atlântico Sul (ENOS). Essa oscilação pode estar vinculada ao fenômeno El Niño e La Niña. Segundo Drumond; Ambrizzi (2003); Ropelwskian et al. (1994), Souza et al. (2000), o El Niño e a La Niña são alterações da temperatura dos oceanos que desencadeiam flutuações na atmosfera, alterando os padrões dos ventos. Suas ocorrências alteram o deslocamento da ZCAS, entre o Pacífico Central, região da Indonésia, e o oeste da costa da América do Sul. Quando intensos, interferem no mecanismo da ZCAS, mudando a ocorrência as precipitações. No caso da bacia hidrográfica do litoral, as estações de estiagem e as chuvas estão diretamente vinculadas a esses eventos.

O clima se constitui da atuação atmosférica que se forma sob a intervenção de forças da energia cósmica que intervêm internamente e em cadeia 
num desdobramento de sua amplitude e magnitude conforme sua força e os fatores geográficos em cada área.

Segundo Matsuoka et al. (2006), as explosões solares de grande intensidade ocorrem em ciclos de aproximadamente 11 anos, cuja carga energética injeta uma nuvem de plasma sobre a Terra e provoca perturbações no campo geomagnético do planeta. Nas áreas onde essa faixa de proteção é pouco extensa, ocorrem intervenções nas ondas de rádio, nos satélites de comunicação e no posicionamento global. O fluxo dessa energia é visualizada nos pólos, por ocasião da Aurora Boreal ou Austral. Nos oceanos Atlântico Norte e Sul essa interferência é denominada Oscilação do Atlântico. Segundo o autor, a injeção do plasma solar exerce intervenção na atmosfera global, ocasionando alterações no ciclo das chuvas, como as ocorridas em 09.03.1989 e 28.10.2003, esta última considerada a maior do século XX.

A ação exercida por essas forças da energia cósmica atuam em ciclos temporal e cósmico, que alteram o clima na terra e que podem ser observados nas estruturas e nas camadas expostas do relevo.

No caso da bacia do litoral, os fluxos de energia solares interferem no planeta interna e externamente, dando origem aos processos tectônicos, vulcânicos e climáticos que vão modelar a superfície, delineando formas identificadas como: serras, depressão sertaneja, tabuleiros pré-litorâneos e planície litorânea. A Figura 1 (mapa Geomorfológico da Bacia Hidrográfica do Litoral - CE) traz espacializada a rede da bacia hidrográfica com a sua morfologia, permitindo que se tenha uma noção de sua distribuição e a formação de suas paisagens.

As paisagens que se delineiam sobre o corpo terrestre nada mais são que uma resposta da natureza à força criadora energética e são visualizadas conforme sua distribuição temporal e espacial. Os arranjos dos componentes abióticos e bióticos formam um conjunto homogêneo que - visualizado e identificado - vai também compor as paisagens.

$\mathrm{Na}$ área da presente pesquisa, o formato da bacia e seu modelado definem o arranjo das paisagens identificadas pelo maior ou menor índice de aridez.

As condicionantes naturais - estar próximo ou distante do mar, posicionado na direção da entrada das massas atmosférica, encontrar-se em áreas elevadas ou rebaixadas - são peculiaridades que vão condicionar o arranjo dessa paisagem específica, ou seja, o arranjo da morfologia em contato com essas massas vão definir a paisagem analisada. 


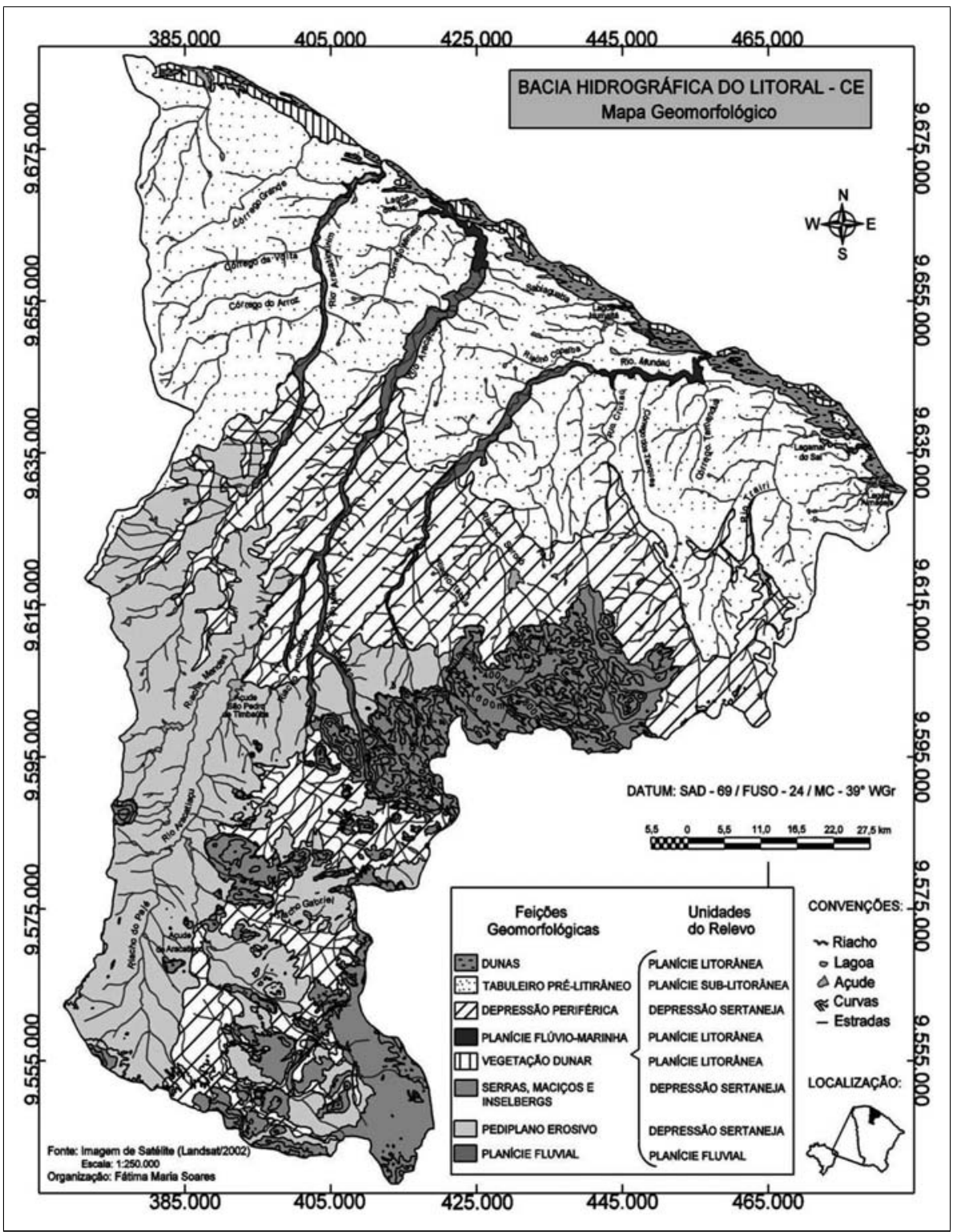

Figura 1: Mapa Geomorfológico / Bacia Hidrográfica do Litoral - CE.

Fonte: Soares Kelting (2006), elaborado a partir de imagem de Satélite Landsat (2002). 
Todo o processo funciona em cadeia, ação que atua de forma vertical, que compreende acoplamento oceano-atmosfera, que ao agir sobre superfície e subsuperfície criam condições de vida formando paisagem. A materialização se dá tanto pela visualização da fisionomia do relevo com sua cobertura vegetal (o visível), premissa de identificação da paisagem, como também pelas formas de uso agrícola da terra que se desenvolve conforme sua capacidade de cultivo.

Na bacia do litoral a forma de apropriação da paisagem pela sociedade ocorre com o uso de práticas agropastoril e extrativa, herdadas pelos antigos habitantes da área - os índios. A relação estabelecida entre essa sociedade e a natureza, deixa os indivíduos vulneráveis, sempre à mercê da sazonalidade climática, do período de secas e de chuvas que são condicionantes do clima semiárido.

No período em estudo, de 1971 a 2007, as ocorrências cíclicas temporais podem ser visualizadas no Quadro 1, que apresenta os anos de eventos do El Niño, da La Niña e dos Neutros - ocorrências do aumento e da diminuição da temperatura do Oceano Pacífico Equatorial e Tropical.

Quadro 1: Anos dos Eventos de El Niño, La Niña e Neutros entre 1970-2007.

\begin{tabular}{|c|c|c|c|c|}
\hline El Niño & $\begin{array}{c}\text { Intensidade do } \\
\text { evento }\end{array}$ & La Niña & $\begin{array}{c}\text { Intensidade do } \\
\text { evento }\end{array}$ & Anos Neutros \\
\hline $1972-1973$ & Forte & $1970-1971$ & Moderado & $1977-1978$ \\
\hline $1976-1977$ & Fraco & $1973-1976$ & Forte & $1978-1979$ \\
\hline $1977-1978$ & Fraco & $1983-1984$ & Fraco & $1979-1980$ \\
\hline $1979-1980$ & Fraco & $1988-1989$ & Forte & $1980-1981$ \\
\hline $1982-1983$ & Forte & $1995-1996$ & Fraco & $1981-1982$ \\
\hline $1986-1988$ & Moderado & $1998-1999$ & Moderado & $1983-1984$ \\
\hline $1990-1993$ & Forte & $1999-2000$ & Moderado & $1985-1986$ \\
\hline $1994-1995$ & Moderado & & & $1989-1990$ \\
\hline $1997-1998$ & Forte & & & $1990-1991$ \\
\hline $2002-2003$ & Moderado & & & $1996-1997$ \\
\hline $2004-2005$ & Fraco & & & $2000-2001$ \\
\hline $2006-2007$ & Fraco & & & $2001-2002$ \\
\hline & & & & $2003-2004$ \\
\hline & & & & \\
\hline
\end{tabular}

Fonte: Modificada INPE/CPTEC (2008). 
Os municípios que formam a bacia hidrográfica do litoral, Amontada, Miraíma, Aracatiaçu, Irauçuba, Itapipoca, Trairi, Tururu e Uruburetama, apresentam características de paisagem diferenciada em decorrência da forte influência do fator geográfico.

A partir da série pluviométrica entre 1971 e 2007, fornecida pela Sudene/Funceme, passou-se a identificar uma acentuada variabilidade temporal e espacial das chuvas, conforme Figura 2, variação essa ocasionada pela quantidade de chuvas ao longo dos anos. Municípios como Irauçuba vão apresentar média pluviométrica em torno de $490 \mathrm{~mm}$ /anuais, em que a série foi identificada nos anos como 1993 e 1998 com quantidade pluviométrica anual de 130 mm/anuais. Comparado esse mesmo período ao município de Trairi, o que detém maior média anual - $1300 \mathrm{~mm} / \mathrm{anuais} \mathrm{-} \mathrm{encontraremos}$ baixa quantidade anual de chuva, em especial em 1993, registro de $470 \mathrm{~mm} /$ anuais.

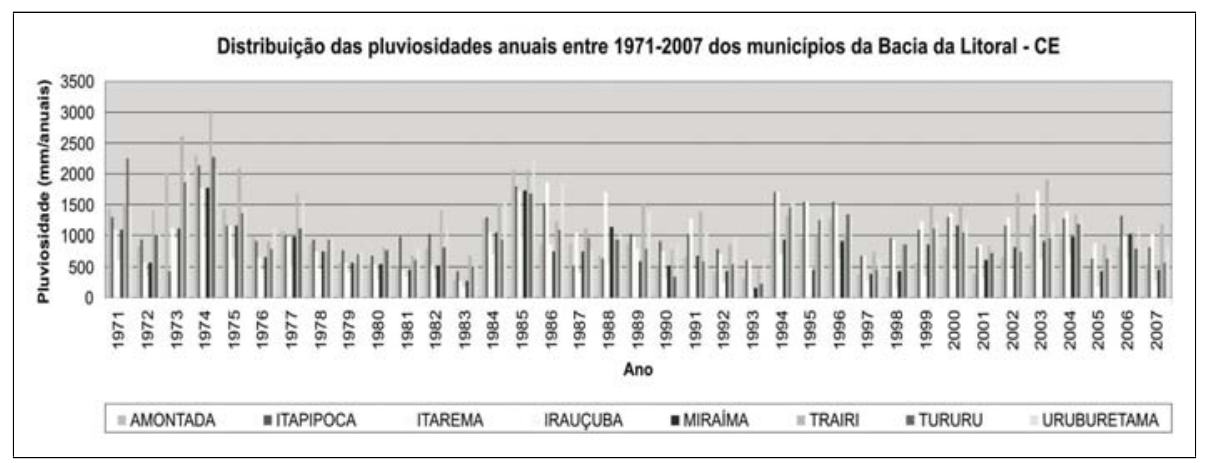

Figura 2: Gráfico da série histórica pluvimétrica dos municípios da Bacia do Litoral - CE.

Fonte: SUDENE/FUNCEME, série histórica entre (1971-2007).

Os dois exemplos fortalecem o argumento do controle do regime semiárido da distribuição das chuvas, sejam elas no litoral ou numa área que apresente dificuldade para entrada de massa atmosférica, como Irauçuba.

Observa-se que mesmo nas áreas onde a pluviosidade se encontra em média acima de $1000 \mathrm{~mm} / \mathrm{anuais,} \mathrm{a} \mathrm{temporalidade} \mathrm{e} \mathrm{ciclicidade} \mathrm{das} \mathrm{chuvas}$ e a distribuição espacial são controladas por esse tipo de clima que vai refletir na cobertura vegetal. 
Sendo a sazonalidade das chuvas característica do semiárido, a flutuação temporal e espacial das chuvas está atrelada à dinâmica atmosférica global. No entanto, a variabilidade das precipitações temporal e espacial tem como fator regulador a forma semicircular da bacia, a orografia e a localização geográfica, relação entre massas atmosféricas quando em ação na superfície da bacia. Conforme a intensidade ou não das massas atmosféricas, esses fatores vão alterar o gradiente de pressão que intervém na umidade, o que, por cadeia, vai interferir na distribuição das chuvas. Resultante disso são áreas de maior ou menor aridez.

O Quadro 2 apresenta as médias pluviométricas da série, o desvio padrão e o coeficiente de variância, dos quais faremos análise a seguir.

Quadro 2: Média pluviométrica, desvio padrão, e coeficiente de variância dos municípios que formam a bacia do litoral - Estado do Ceará, 1971-2007.

\begin{tabular}{|l|c|c|c|}
\hline \multicolumn{1}{|c|}{ Municípios } & Médias Pluviométricas & Desvio Padrão & $\begin{array}{c}\text { Coeficiente de Vari- } \\
\text { ância }\end{array}$ \\
\hline Amontada & 881,6 & 484,8 & 54,99 \\
\hline Itapipoca & 1054,3 & 390,0 & 36,99 \\
\hline Itarema & 1061,6 & 427,8 & 40,29 \\
\hline Irauçuba & 492,3 & 237,6 & 48,26 \\
\hline Miraíma & 773,4 & 358,2 & 46,31 \\
\hline Trairi & 1265,0 & 562,1 & 44,43 \\
\hline Tururu & 979,0 & 421,3 & 43,03 \\
\hline Uruburetama & 1162,8 & 422,6 & 36,34 \\
\hline
\end{tabular}

Fonte: SUDENE-FUNCEME (1971-2007).

A média pluviométrica de Irauçuba, em 492 mm/anuais, é decorrente de dois fatores: i) localizar-se o município a sotaventos do Maciço de Uruburetama; ii) ser posicionado num local onde as massas atmosféricas, ao circundarem a bacia, em formato de um semicírculo, não dispõem de umidade, o que acentua a aridez. Os municípios de Itarema, Itapipoca e Trairi, com índice acima de $1000 \mathrm{~mm} /$ anuais estão no litoral, posicionados na direção da entrada das massas, beneficiando-se com mais chuvas. O mesmo não ocorre com Amontada que, apesar de encontrar-se na faixa litorânea, recebe menor influência das massas, apresentando média de 890 mm/anuais. O município de Tururu, apesar de não se encontrar no litoral, apresenta média $979 \mathrm{~mm} / a n u a i s$, quantidade de chuvas decorrente de sua 
posição geográfica, no sopé do Maciço de Uruburetama, a barvalento, o que lhe favorece as precipitações. A direção nordeste/leste da entrada das massas atmosféricas vão também beneficiar Uruburetama, pois parte do Maciço está em posição favorável. Miraíma, por se encontrar no meio da bacia hidrográfica, apresenta $773 \mathrm{~mm} /$ anuais. Ao analisar o município de Trairi, sua média de precipitação o classificaria como de tropical úmido, mas o índice de coeficiência de variância o re-classifica como um sistema controlado pelo clima semiárido.

Entre as características do clima semiárido está a intensa evapotranspiração e o déficit hídrico durante os meses de estiagem. As chuvas ocorrem durante três a quatro meses, período que corresponde ao verão/outono. As temperaturas são elevadas durante todo o ano, com média $26^{\circ} \mathrm{C}$, insolação com duração entre 8 (oito) a 9 (nove) horas diárias, sob intensa radiação solar. As variações das temperaturas, diurna e noturna, alteram o gradiente de pressão, cujo efeito oscilatório se reflete na paisagem.

Conforme o Quadro 2, por meio dos índices de coeficiência de variância foi possível diagnosticar que grande parte dos municípios apresenta irregularidade quanto à distribuição das chuvas. O município de Amontada forneceu o indicador de maior variabilidade em seu período chuvoso, índice de 54,99, enquanto Uruburetama índice de 36,34 - maior regularidade pluviométrica.

Esses índices sugerem que o município de Amontada é aquele que, entre os demais, tem maior variação temporal das chuvas, enquanto Uruburetama é aquele com baixa variação em seu ciclo, ou seja, o que apresenta maior estabilidade temporal de chuvas.

Os índices apresentados pelo desvio padrão são indicadores da vulnerabilidade de escassez hídrica em toda a bacia hidrográfica. É por essa informação que o poder público tem argumentos para implementar projetos que visem a acumular e a gerenciar as águas para o período de estiagem.

O efeito das massas sobre a superfície vai desencadear processos físico-químicos, cujas reações são observadas em campo a partir dos esfacelamentos das rochas e da cobertura vegetal.

A ação do clima semiárido sobre a superfície da crosta, na bacia hidrográfica do litoral, possibilitou a formação de solos ralos nas depressões sertanejas, de solos coluvionais, espessos e argilosos, nos sopé do Maciço e em suas vertentes a barvalento. Nas proximidades do litoral, favoreceu a formação de depósitos aluvionais e eólicos que cobrem o tabuleiro prélitorâneo, e formações dunares. 
A ação atmosférica, no passado, que definiu o regime pluviométrico das chuvas, propiciou o desenvolvimento de um ambiente denominado semiárido. Na faixa litorânea, essa ação pode ser observada pelo transporte de sedimento de praia para o continente e formação de dunas.

A paisagem apresenta - para quem a observa do litoral para o sertão - unidades de relevo representativas do florescimento de vegetação de caatinga que se alternam com lavouras de subsistência.

No Maciço, em sua vertente úmida, encontra-se uma diversidade de espécies florísticas, entre caatinga arbórea, mata pluvio-nebular e algumas espécies de mata atlântica. Na faixa litorânea, a cobertura vegetal é um complexo entre vegetação de caatinga e dunar, como o murici (Byrsonima sp).

No caso específico da bacia hidrográfica do litoral, o comportamento das massas de ar que fluem para o Estado, e, em especial para essa área, tem como fortes elementos bloqueadores a topografia e a configuração da bacia. Essas duas condicionantes vão aprisionar as massas que, ao movimentar-se em círculo, recebem forte influência de superfície, ressecando, e reduzindo as chuvas.

A característica ambiental dessa bacia fornece indicações de que há escassez hídrica sazonalmente; o recurso em superfície evapora ou escoa, e para armazenar água que garanta a sobrevivência das comunidades é necessária a implantação de medidas de intervenção ao longo da história de formação social do estado do Ceará. Na busca em atender a demanda da população, foram construídos 4 (quatro) açudes de médio porte (conforme Quadro 3), e 225 açudes de pequeno porte. A importância desses reservatórios está no abastecimento das sedes dos municípios e na utilização dos sangradouros para a produção agrícola.

Quadro 3: Açudes para abastecimento de água potável em municípios da Bacia Hidrográfica do Litoral - CE.

\begin{tabular}{|l|l|c|}
\hline \multicolumn{1}{|c|}{ Municípios } & \multicolumn{1}{|c|}{ Nome reservatório } & Capacidade $\left(\mathbf{M}^{3}\right)$ \\
\hline \multirow{2}{*}{ Itapipoca } & Poço Verde & $13.657,999$ \\
\cline { 2 - 3 } & Quandu & $4.000,000$ \\
\hline Miraíma & S. Pedro Timbaúba & $19.259,000$ \\
\hline Uruburetama & Mundaú & $21.308,000$ \\
\hline Total & & $58.224,999$ \\
\hline
\end{tabular}

Fonte: Anuário Estatístico do Ceará (2000). 
Entre os reservatórios de médio porte estão o Poço Verde em Itapipoca, o São Pedro de Timbaúba em Miraíma, e o Mundaú em Uruburetama, com capacidade para suportar 2 (dois) anos sem chuvas. Entretanto, os 58 milhões $/ \mathrm{m}^{3}$ não são suficientes para atender às necessidades das populações, em especial, àqueles que residem nas pequenas comunidades.

Para reduzir os impactos causados pela falta de água em superfície, a Companhia de Produção de Recursos Minerais - CPRM (2004) gerenciou a perfuração de poços artesianos. O objetivo era acabar com a falta de água nas comunidades, no entanto, a política de perfuração de poços não atendeu às expectativas, uma vez que os poços perfurados nas depressões sertanejas, seus aquíferos, apresentavam alto teor de sais. A falta de recursos hídricos (água potável) para abastecer as populações no sertão nordestino se arrasta pelos séculos e os problemas sociais advindos de sua escassez atinge magnitude, pois, além dos problemas de saúde pública gerados, há um comprometimento na produção de alimentos de subsistência.

A sazonalidade das chuvas é uma condicionante natural, mas a falta de recursos hídricos tem a ver com implantação de política pública efetiva no que concerne à armazenagem e à distribuição das águas das chuvas, em especial, nessa bacia hidrográfica.

O acesso à água se limita à sede e aos distritos. As pequenas localidades e os sitiantes continuam à mercê do período das chuvas, e por ocasião da estiagem o problema secular se repete.

Na busca de fornecer água à população do semiárido, o Governo Federal deu início a um programa de perfuração de poços tubular, conforme demonstrado no Quadro 4.

Quadro 4: Número de poços tubulares por Município da Bacia do Litoral - CE.

\begin{tabular}{|l|c|c|}
\hline \multicolumn{1}{|c|}{ Municípios } & Número de poços & \% \\
\hline Amontada & 13 & 3,84 \\
\hline Irauçuba & 37 & 10,92 \\
\hline Itapipoca & 84 & 24,77 \\
\hline Itarema & 118 & 34,80 \\
\hline Miraíma & 2 & 0,58 \\
\hline Trairi & 31 & 9,16 \\
\hline Tururu & 7 & 2,07 \\
\hline Uruburetama & 47 & 13,86 \\
\hline Total & 339 & 100 \\
\hline
\end{tabular}

Fonte: CPRM (2004). 
A partir do Quadro 4, é possível diagnosticar que, dos 339 poços perfurados ao longo da bacia, 34,80\% se encontram em Itarema e 24,77\% em Itapipoca. Segundo informações da CPRM (2004), apenas os poços perfurados em sedimentares e aluvionais dispõem de melhor qualidade. Mesmo identificando restrições com relação à qualidade da água para consumo, $13,86 \%$ dos poços estão em Uruburetama, 10,82\% em Irauçuba, e 9\% no Trairi. Apesar de haver tentativa por parte da CPRM de perfurar poços em terrenos cristalinos, para captação de aquífero fissural, pouco sucesso temse obtido, em decorrência do baixo potencial hidrológico e da salinidade da água.

Segundo Brandão (2003), a escassez hídrica em superfície é ocasionada pelo curto período pluviométrico determinante do clima semiárido; no caso da bacia hidrográfica do litoral, as águas acumuladas evaporam ou percolam. Sendo o substrato rochoso constituído por rochas ígneas e metamórficas, a percolação condicionada pelos sistemas de fraturas vai contribuir para o armazenamento de água subterrânea.

Os poços têm um papel importante na fixação das comunidades no campo; a água extraída desses mananciais oferece condições às famílias de permanecerem na zona rural, de alimentarem os animais e de esperarem as chuvas do ano seguinte.

O projeto de perfuração de poços vem sendo dinamizado a uns 8 (oito) anos e faz parte do programa de recursos hídricos implantado pelo Governo do Ceará. Consiste na ideia da perenização dos rios e na interligação das bacias hidrográficas através de barragens, açudes de médio porte, adutoras, sistema de irrigação nos vales em que as condições edafoclimáticas são adequadas, e perfurações de poços nas comunidades em que a rede de drenagem está fora das áreas de perenização. Com esse projeto espera-se que, num futuro próximo, a falta de água para abastecimento doméstico e animal seja suprida.

Apesar do projeto de recursos hídricos em andamento, o problema da água continua sem solução, os açudes nessa bacia hidrográfica não têm capacidade suficiente para enfrentar anos de seca, e o número de poços ainda é insuficiente para atender todos os povoados e vilas que estão na zona rural.

A falta de água para o abastecimento das comunidades sempre foi um problema na região semiárida, e na bacia do litoral cearense não podia ser diferente. Esse problema vem se repetindo lentamente há séculos, e mesmo a cada estação prolongada de chuva as famílias se veem sem água para o 
consumo humano e animal, pois não têm condições de acumular, satisfatoriamente, a água.

Para minimizar essa dificuldade, foi elaborado - paralelamente à ideia de perfuração de poços - o projeto de instalação de cisternas em comunidades rurais do semiárido para o armazenamento e o abastecimento domiciliar de água. Esse projeto, sob a responsabilidade da CARITASArquidioceses que, junto com a Esplar-Empresa de Planejamento (2008), fizeram levantamento da demanda e da seleção onde seriam instalados os reservatórios. Foram beneficiadas comunidades, ou sitiantes, que não dispunham de água potável. O projeto consiste em fornecer a cada família uma caixa de 1000 litros, devidamente vedada, com instalações para captação das águas de chuva. A bacia do litoral (quadro 05) apresenta a distribuição de cisternas nos municípios, das quais 45,39\% estão localizadas no município de Irauçuba, 25,25\% em Itapipoca, 14,80\% nos municípios de Trairi, e 9,70\% em Miraíma, seguido de Amontada, com 4,86\%.

Quadro 5: Número de Cisternas por Município da Bacia do Litoral - CE.

\begin{tabular}{|l|c|c|}
\hline \multicolumn{1}{|c|}{ Municípios } & Número de Cisternas & \% \\
\hline Amontada & 20 & $4,86 \%$ \\
\hline Miraíma & 40 & $9,70 \%$ \\
\hline Itapipoca & 104 & $25,25 \%$ \\
\hline Irauçuba & 187 & $45,39 \%$ \\
\hline Trairi & 61 & $14,80 \%$ \\
\hline Total & 412 & $100 \%$ \\
\hline
\end{tabular}

Fonte: Esplar (2008).

A iniciativa da instalação das cisternas tem como meta alcançar dois grandes problemas - garantir água no período de estiagem e melhorar as condições de saúde da população.

A irregularidade das chuvas nessa região é um dos fatores que definem a bacia hidrográfica como uma das mais áridas do estado do Ceará, onde o fator vulnerabilidade concentra-se na população que vive na zona rural e continua ao sabor do período chuvoso.

As paisagens locais da pesquisa pouco de alteram, exceto em áreas pontuais: pequenas comunidades que desenvolvem suas práticas agropecuárias tradicionais. 


\section{Procedimentos metodológicos}

Para o desenvolvimento desta pesquisa foram utilizados objetivos práticos em forma de estudo explicativo, dados fornecidos por bibliografias, relatórios técnicos, dados censitários, e coleta em campo.

\section{Dados censitários}

Com base numa série de 34 anos (1971-2007), dados fornecidos pela SUDENE-FUNCEME foram efetuados, em média, desvio padrão e coeficiente de variância, retrabalhamento estatístico-matemático, que propiciou analisar as informações e ter subsídios capazes de fortalecer os argumentos da predominância do clima semiárido para a bacia hidrográfica do litoral do Ceará.

Os dados sobre Poços Tubulares foram coletados na CPRM - Companhia de Produção de Recursos Minerais (2004).

Os dados sobre a instalação de cisternas foram obtidos na Esplar Empresa de Serviços e Planejamento (2004).

Os dados sobre o número de açudes e a capacidade de armazenagem e abastecimento de água potável coletado foram fornecidos pelo Anuário Estatístico do Ceará (2000).

\section{Dados de campo}

Registro fotográfico coletado durante reconhecimento da área de estudo.

\section{Dados de Representação}

Mapa de localização da área. Efetuado a partir da Imagem de Satélite - CBERS (2002). 


\section{Considerações finais}

Os dados coletados e analisados possibilitaram diagnosticar que a sazonalidade e a distribuição das chuvas constituem um padrão do regime climático semiárido. Esse tipo de clima forma uma paisagem que tem forte influência de fatores geográficos, topográficos e de localização espacial dentro da bacia hidrográfica. As paisagens no semiárido são identificadas, inicialmente, pela morfologia que, associada ao comportamento das chuvas, ratificam seu índice de aridez. As mudanças da paisagem, no caso específico da bacia hidrográfica, são decorrentes da implantação de projetos que visam atender às necessidades hídricas da população ali residente.

Entretanto, apesar da implantação de políticas públicas que propiciem um aumento no volume de armazenagem, e criação de comitê para gerenciar as águas, a população continua vulnerável aos ciclos de estiagem e de seca.

Observa-se que a água na região continua de difícil acesso pela população, em especial, pelas pequenas comunidades e sitiantes, que permanecem ao capricho do ciclo das chuvas, o que compromete sua produção agrícola e, portanto, seu sustento.

A aplicação de dados estatísticos e das medidas de análise tais como média, desvio padrão e coeficiente de variância, aplicada à série pluviométrica (entre 1971-2007) forneceram indicadores que reforçam a sazonalidade e a irregularidade no regime pluviométrico da semiaridez.

Todos os dados coletados e analisados são indicadores da ciclicidade das estações seca e chuvosa, e do despreparo da população para enfrentar a oscilação da natureza.

O padrão de distribuição de chuvas, que fortalece os anos de escassez hídrica, funciona como parâmetro a ser levado em consideração por ocasião de políticas públicas de gestão hídrica no semiárido.

\section{Referências}

BRANDÃO, Ricardo de Lima. Zoneamento Geoambiental da Região de Irauçuba - CE. Fortaleza: CPRM, 2003.

BRASIL. Superintendência de Desenvolvimento do Nordeste-SUDENE - 1984. 
CARVALHO, L. M. V.; JONES, C.; LIEBMANN, B. The South Atlantic convergence zone: intensity, form, persistence, relationships with intraseasonal to interannual activity and extreme rainfall. Journal of Climate. Boston, v. 17, p. 88-108, July 2004.

CEARÁ. Secretaria de recursos hídricos do Ceará (1999).

. Anuário Estatístico do Ceará - IPECE - 2000.

. Fundação Cearense de Meteorologia - FUNCEME - 1984-2000.

DRUMOND, A. R. M.; AMBRIZZI, T. Estudo observacional e numérico da variação da circulação atmosférica nas Américas em episódios extremos da Oscilação Sul. Revista Brasileira de Meteorologia. v. 18, p. 1-12, 2003.

ESPLAR - Empresa de Serviços e Planejamento. Fortaleza: CE, 2004.

KANDEL, Robert. A Evolução dos Climas. Lisboa: Terramar, 1990. In: KAROLY, d.j., Southern hemisphere circulation features associated with El Niño - Southern Oscillation Events. Journal of Climate, v. 2, p. 1239-1252, 1989.

KOUSKY, V. E.; KAYANO, M. T. Principal Modes of outgoing longwave radiation and 250-mb circulation for the South American sector. Journal of Climate, v. 7, p. 1131-1143, July 1994.

LEGGETT, Jeremy. Aquecimento Global. O Relatório do Greenpeace. RJ: Fundação Getúlio Vargas, 1992.

MADDEN, R. A.; JULIAN, P. R. Observations of the 40-50 day tropical oscillations - A Review. Monthly Weather Review, v. 122, p. 814-837, May 1994.

MARENGO MARENGO J. A. (Authors) Onset and End of the Rainy Season in the Brazilian Amazon Basin. Journal of Climate, v. 14, p. 833-852, Mar. 2001.

MATSUOKA, Marcelo Tomio; CAMARGO, Paulo de Oliveira; BATISTA, Inez Staciarini. Impacto de Explosões Solares no Comportamento da Ionosfera e no Posicionamento cpm GPS na Região Brasileira: Estudo de caso para o dia 28 de outubro de 2003. Bol. Ciência Ged. sec. Artigos, Curitiba, v. 12, n. 2, p. 315-334, jul-dez, 2006.

MUZA, Michel Nobre; CARVALHO, Leila M. Véspeli, Variabilidade Intrasazonal e Intranual de Extremos na Precipitação sobre o Centro-Sul da Amazônia durante o verão Austral. Revista Brasileira de Meteorologia, v. 21, n 3, 29-41, 2006.

NOBRE, C. A.; SELLERS, P. J.; SHUKLA, J. Amazonian deforestation and regional climate change. Journal of Climate, v. 4, p. 957-987. 1991.

OUZA, E. B. de; KAYANO, M. T.; TOTA, J.; PEZZI, L.; FISCH, G.; NOBRE, C. On the Influences of the El Niño, La Niña and Atlantic dipole pattern on the Amazonian Rainfall during 1960-1998. Acta Amazonica, v. 30, p. 305-318. 2000.

ROPELEWSKI, C. H.; HALPERT, S., Global and regional scale precipitation patterns associated with the El Niño/Southern Oscillation. Monthly Weather Review, v. 115, p. 1606-1626, Jan. 1987.

SILVA, Vicente de Paulo Rodrigues da; DANTAS, Renilson Targino; CAVALCANTI, Enilson Palmeira. Influência do fenômeno El Niño no rendimento da cultura do algodão no Estado da Paraíba. In: X Congresso Brasileiro de Meteorologia, 1998, BRASÍLIA. 
SOUZA, E. B. de; KAYANO, M. T.; AMBRIZZI, T. The Regional Precipitation Over the Eastern Amazon/Northeast Brazil Modulated by Tropical Pacific and Atlantic SST Anomalies on Weekly Timescale. Revista Brasileira de Meteorologia, v. 19, p. 325-336. 2004.

WEICKMANN, K. M.; LUSSKY, G. R.; KUKBACH, J. E. Intraseasonal (30-60 day) fluctuation of outgoing longwave radiation and $250 \mathrm{mb}$ stream function during northern winter. Monthly Weather Review, v. 113, p. 941-961, June 1985.

XAVIER, Teresinha de Maria Bezerra S. Tempo de chuva. Estudos Climáticos e do Ceará. Previsão para o Ceará e Nordeste Setentrional. Fortaleza: Editora ABC, 2001.

Fátima Maria Soares - Professora do departamento de Geografia da Universidade Federal do Ceará.

Recebido para publicação em Setembro de 2009 Aceito para publicação em Novembro de 2009 